\title{
24
}

\section{Revisiting Governance Systems Analysis in Northern Australia: Exploring Critical Systems Thinking as a Framework for Engaging with Multiplicity and Incommensurability}

\author{
Anne Stephens, Elspeth Oppermann \\ and Allan P. Dale
}

\section{Introduction}

Northern Australia, the region of Australia north of the Tropic of Capricorn, is characterised by profound difference and complexity in cultures, worldviews and ways of being. An array of diverse governance responses to the way this complexity and difference manifests itself has been discussed elsewhere (Stephens et al., 2014). This chapter reflects, in particular, on the use of Governance Systems Analysis (GSA) in Northern Australia in improving governance outcomes in this complex world. GSA is an analytical tool deployed to support deliberative dialogue among those involved in complex governance systems and contexts in the north. To date, its most common use has been in the mobilisation of the dominant norms of governmental practice to resolve complex problems at a landscape scale. In the context of multiplicity and incommensurability of different ways of being, this chapter seeks to enhance GSA's ability to engage explicitly and ethically with genuine cultural difference embedded 
within Northern Australian society. It uses Critical Systems Thinking (CST) to revisit, through systems thinking, GSA's structural-functionalist foundations. The chapter's objective is to enhance an approach to complex problem solving that is already used in Northern Australia to support practical policy engagements.

GSA has been developed to analyse complex problems of governance in socio-environmental contexts in Northern Australia (Dale, 2013, 2014). As a broad analytical method, it was first published and developed by Dale, Vella and Potts (2013). Its earlier conceptual origins emerged from methods used to explore complex policy failures in Indigenous affairs and later in social impact assessment methods (Dale, 1993; Dale \& Lane, 1993). Its most significant application is its use to facilitate deliberative dialogue between government agents and stakeholders responsible for the protection of the Great Barrier Reef. In this case, it explores the deficiencies of the present governance arrangements in attaining desired ecological, social and economic outcomes (Dale, Vella, Pressey et al., 2013). Latent within this approach is a concern to give voice to disempowered populations who are intimately connected in complex ways to various geographies and landscapes.

In engaging with the question of governance in Northern Australia, GSA wades into the profound question of 'what is governance', comprising the questions of how to govern ethically and, indeed, how to ethically develop governance systems per se. In contrast to other parts of Australia, Northern Australia is notable in that, when considering the wider governance system, it must be accepted that, alongside a Western system of governance, there is an array of active Indigenous systems of governance (Christie, 2014; Prout \& Howitt, 2009) that have remained strong despite colonisation. These Indigenous governance systems are often unknown, unrecognised or misunderstood by dominant Australian society, and there are longrunning, tragic policy failures emerging from one form of governance attempting to ignore or co-opt the other and positive and creative generative adaptations and co-productions of integrated governance practices (McMullen, 2013; Trudgen, 2012; Verran, 2011). These multiple accounts of government, but also the state, land and country, and the fabric of reality itself are embedded in, and come into conflict through, a highly contested socio-ecological landscape (Woinarski, 2014). Further, rather than just seeking to govern society as if it were an extant and immutable object, forms of governance actively produce our wider northern society (Stephens et al., 2014). As such, not only 'what' is 
governed but how that governance occurs is a deeply significant question for determining what ways of life, identity and ecology are (re)produced in Northern Australia.

Destructive and productive encounters between governance systems and the forms of life they produce are not confined to the intersections of Indigenous and non-Indigenous worlds (Stephens et al., 2014). However, Northern Australia demonstrates the profound implications of multiplicity and incommensurability of ways of being, challenging Western assumptions of an 'ideal' system of governance and governance practices based on consensus. These assumptions authorise the occlusion or absorption of other ways of life into the dominant governance system and its attendant identity of the neoliberal subject (Peck \& Tickell, 2002). The devastating impact of such agendas on Indigenous identity, wellbeing and health is well known (Trudgen, 2012). Yet the region continues to be subject to ever more intensive forms of political intervention with transformational objectives (Anderson, 2015), such as through the Northern Territory Emergency Response and, more recently, the Indigenous Advancement Strategy. Policy approaches, including those that embed corporate governance, are some of the carriers of these transformational agendas, precursors to complex encounters with Indigenous forms of governance and ecological governance (Christie, 2006). This makes Northern Australia an excellent case study for exploring governance and difference that is not so clear elsewhere. It also provokes GSA to consider its own inherent assumptions about the nature of governance, enabling the explicit development of an ethical practice for its intervention into governance systems that is cognisant of the multiplicity of governance systems and ways of being.

On the basis of GSA's ontological foundation in systems thinking and because of our concern to develop and address GSA's ability to engage with questions of multiplicity and incommensurability, we propose CST as an appropriate framework to engage with GSA, as it has emerged from a similar ontological foundation (Jackson, 1991; Midgley, 1996). This chapter uses CST's core commitments or principles of practice to enable ongoing critical reflexivity during the analysis of, and intervention in, each stage of governance activity described in the GSA process. The objective is to develop GSA into a more nuanced analysis and intervention tool for governance systems, capable of acknowledging and engaging with its own contingency and the contingency of the systems it is analysing. Doing so allows multiplicity and incommensurability to be acknowledged, 
which enables the explicit political and ethical consideration of practice. The next section introduces GSA itself, followed by an account of why incommensurability and multiplicity, which characterise Northern Australia, pose a challenge to GSA's current form. CST is then put forward as a useful way to render GSA more capable of supporting different ways of being in Northern Australia.

\section{Origin and Use of Governance Systems Analysis}

GSA has been used, primarily in Northern Australia, as a way to seek systemic reform in government-driven interventions. In Australia, a number of empirically and theoretically grounded frameworks have been developed to analyse and evaluate natural resource governance systems and other complex systems, including their constituent plans, programs, strategies and institutions (Althaus et al., 2007; Bellamy et al., 2001; Connick \& Innes, 2003; Curtis et al., 1998; Hajkowicz, 2009; Turnbull, 2005; Vogel, 2011). While it is widely recognised that governance systems operate in a non-linear, systemic fashion, they are not always analysed in this way (Abrahams, 2005; Carman, 2007; Hoggarth, 2010; Plummer \& Armitage, 2007; Rauschmayer et al., 2009). Thus, GSA was developed to deal with the management of complex governance contexts such as complex landscape management and natural resource management (NRM) (see Dale, Vella \& Potts, 2013).

The GSA framework is grounded in structural-functionalism to help analyse real-world governance systems. Accordingly, it attempts to bring into focus the interactions of governance system structures, functions and their impact on the likelihood of the system delivering its desired outcomes (Dale, Vella \& Potts, 2013). Structures tend to be the more static elements of systems and include networks and alliances of individuals and institutions that contribute independently and collectively towards the delivery of key system outputs, such as plans, strategies, research, implementation and monitoring and, consequently, outcomes such as improved water quality and human health outcomes. Functions, on the other hand, are the characteristics that emerge as a property of the relationship between structural components in the system. The functionality of the system includes system connectivity, while the agency 
of key players and the role of knowledge are also crucial. While we cannot assume that functions are always deliberate, they can be planned for and viewed as a measure of how governance systems deliver desired outcomes.

Dale, Vella and Potts (2013) developed GSA to apply structuralfunctionalist concepts to support deliberative dialogue within society about securing continuous improvement in extant governance systems. It is, to some extent, assumed that structural aspects of any governance system can be enabled by defined concepts of rationality that are commonly inherent on Western processes of policy development. Hence, structural components of governance processes are broadly considered to cover by the following (but non-linear) activities:

- vision and objective setting

- strengths, weaknesses, opportunities and threats analysis and research

- strategy development (within various structural elements of the system)

- implementation

- monitoring, evaluation and review.

The GSA framework seeks dialogue among all participants in a governance system, but particularly decision-makers, to identify which structural and functional components of a governance system are limiting the success of governance activities. The process builds evidence to support reforms, decisions and actions and then focuses attention on supporting improvement and reform in those areas. Governance processes that reduce losses of goodwill, capacity and partnerships, for example, are more likely to enhance governance systems. In Northern Australia, the multiple, overlapping and different jurisdictional and human worldviews add complexity and fragmentation of governance systems within an already contested landscape. This means good policy development and the nurturing of the sound functional integration of structural and functional activities across the governance system needs to be attended to explicitly through overtly collaborative mechanisms. GSA does this effectively within the parameters of a Western policy development norms, but in past applications it has tended to underplay the need to implicitly and explicitly allow different ways of being to coexist, including different ways of doing governance and redefining the different objectives of governance itself (Springer, 2010). Hence, the next section explores why 
this is of importance in theorising governance and how GSA might learn from CST as a mode of engagement with difference that shares its basic systems ontology.

\section{Governance and Difference: Ethical Engagement with Multiplicity and Incommensurability}

In accounting for governance as systemic, we begin by noting the distinction between 'governance' and 'government'. Government refers to the formal institutions of political power and formal policy practices of the nation-state, while governance refers to the broader intentional shaping of the flow of events to realise desired public good (Parker \& Braithwaite, 2003) within a wider governance context. The two are not mutually exclusive. The institution of government crosses over and negotiates the multiple other institutions involved in our societal system of governance, leading to a complex and emergent array of peoples, practices and rationales of governance, including different accounts of the public good (or indeed the 'good public'). The wider notion of the term governance has become more familiar as concepts of network society (Castells, 2000). Globalisation, complexity, liberal governance and advanced liberal governmentality have redefined political practice and analysis (see, for example, Dean \& Hindess, 1998; Lefèvre, 1998). This changing ontology has accounted for politics no longer just being considered as the domain of governments, but, rather, as underpinning the broader practices of societal governance operated by and affecting a much more diverse network of interests and societal problems. Policies and programs that govern are no longer solely designed, implemented or evaluated by government or government agencies alone or a dominant role. Here, governance is understood as inherently systemic. Epistemological approaches to this new ontology have lessened their focus on the structure and form of relatively defined institutions to the nature of relationships between elements that contingently produce an emergent system.

The account of the political context and emancipation also changes in light of this new ontology. Without finite, pre-defined institutions, roles, responsibilities and rights, systemic approaches to governance (including where it is exercised by government) has reopened the meaning of democracy, emancipation and participation (Midgley \& Richardson, 
2007). This shift dovetails with, and in part arises from, post-colonial and post-modern accounts of multiplicity and diversity that reject the notion of universal values and universalising ideals. Having accepted the ontological challenge, debates rage over whether consensus is possible or desirable and how to engage with diversity and plurality and with the people, communities and organisations affected by policy interventions (see Forester, 1999; Lane, 2005; Muro \& Jeffrey, 2008; Parkins \& Mitchell, 2005). The key question is, can we create consensual systems of governance, or is this ideal not only practically unachievable, but ethically fraught? This question is valid and visible in Northern Australia with its diversity and contested/competing post-colonial worlds.

Approaches to these questions vary, but for CST, two main bodies of thought have been central. These are often both termed 'critical theory', but encompass a range of thought, perhaps best epitomised in the thought of critical theorist Jurgen Habermas and the post-structuralist thinker Michel Foucault. Habermas' 'free speech ideal' denotes the conditions free from domination that he argued will permit communicative rationality to produce consensus and a collective way of being that enables improved equality (Ashenden \& Owen, 1999). However, post-structuralists, such as Michel Foucault, argue that the differences and multiplicity of identities, cultures, worldviews and values in society are 'irreducible'-that is, agreement between people in matters of contested social issues may be unlikely, even impossible, due to the incommensurability of worldviews and values and ways of living (Gregory, 1996). From this perspective, efforts to resolve such differences into consensus can be seen as violent, however implicitly, as opting for a single, shared view necessitates the exclusion of elements of other worldviews that are dismantled to reject their validity and integrity. In the context of Northern Australia, for example, one may consider Australia's 'Closing the Gap' policy and program agenda, regarding Indigenous Australians, as being more akin to an assimilationist versus self-determinationist policy divide. Striving for consensus, while recognising worldview differences, might seem like a pragmatic strategy for long-term governance reform.

The consensus-incommensurability divide has major implications for how governance systems are intervened in, by whom and for what purpose. For Habermas, governance systems are ideally the result of, and enable, consensus building through communicative rationality (Bausch, 2001; Beaumont \& Nicholls, 2008; Brocklesby \& Cummings, 1996). Whereas for Foucault, Western forms of governance systems enable 
a particular governmentality — a particular set of technologies and practices that produce a particular form of public good, which, far from being universal, must produce a 'good public' that conforms to this way of life, necessarily at a cost to other ways of being and particular social groups' or individuals' ability to engage in emancipatory practices (Bevir, 2010; Lemke, 2002).

Although it has not explicitly engaged with this debate, GSA, in its use to date, has been aligned more closely to a Habermasian account of communicative rationality. While recognising differing worldviews, the GSA framework has systematically applied a process to derive shared understandings and consensus between the stakeholders of large and complex socio-environmental systems towards their sustainable and planned futures (Dale, Vella \& Potts, 2013; Potts et al., 2014). GSA has traditionally addressed itself to the problem of how to make an extant system more effective in achieving its objectives. It has focused on the pragmatic problem that multilayered systems of governance are not always functionally optimised (Potts et al., 2014). Systems and their objectives can be discordant, redundant or corrupting of the overall system objective and, therefore, require reform. As a practice founded in structuralfunctionalism, however, GSA does recognise the problem of governance as systemic and diverse. Its focus has been to take a more pragmatic approach to reform, which does not seriously challenge a single coherent system as ideal. It has not, therefore, been used to facilitate a radical questioning of systemic goals. Although it has emancipatory concerns, these have not, to date, been fully developed into actionable principles.

CST stands in contrast to this ontology of coherent, knowable and consensual systems. While its literature and practice is heavily influenced by Habermasian thinking, CST practitioners have also been influenced by the post-structural critiques of Habermasian practice and methodologies with approaches such as systemic intervention developed to engage in the politics and ethics of governance systems per se (Brocklesby \& Cummings, 1996; Gregory, 1996; Midgley, 2000; Valero-Silva, 1996). CST responds to the concern that post-structuralists avoid intervention or change for fear of becoming a dominating force that avoids a thorough engagement with what a practice of emancipation might look like itself. Boundaries must be questioned to ensure any practices aimed at making an extant system more effective minimise harmfulness to difference or subjectification. To do this, it is essential that all system participants are 
engaged in the analysis to open up the boundaries as a mode of critique in the first- and second-order modes. Participants question the objectives, goals, functions and structures of the system and the nature of the system, even the paradigms that shape these governance systems themselves. Both GSA and CST practice entail making judgments concerning the boundaries of the systems in question. We argue that, within a more critical theoretical framework, there is a place for both first- and secondorder boundary judgment practices.

The remainder of this chapter advances a methodology that recognises that participants in governance systems are inescapably connected into one or more systems of governance embedded in a wider systemic context and they have agency within that wider system. It endeavours to show how the practical considerations and decisions in a particular empirical context (in this case, the deployment of a GSA-based approach in Northern Australia) may make the resolution of irreducible difference an active political act. This methodological approach acknowledges deliberative ethical practice and, in doing this, we hope to respond to the challenge GSA sets - that is to work with, recognise and identify the extant governance agencies and their interconnections as systems. We hope to develop a method that sees all the analysis and interventions of GSA as inherently supporting political and ethical practices, thereby enabling much deeper engagement with critique and explicit engagement with power and emancipatory actions in conditions of incommensurability and irreducible multiplicities.

\section{Critical Systems Thinking: A Critique of Governance Systems Analysis}

Both GSA and CST have their origins in systems thinking. The fundamental idea of systems thinking is that cause and effect linearity is insufficient to describe complex, changing phenomena that are recognisable and characterised by both the inter-relatedness of their parts and the emergence of properties that cannot be fully comprehended by the system's constituent parts (Flood, 2010; Maani \& Cavana, 2000). There are two systems thinking applications that can be traced back to an ontological shift demarcating a first and second wave of systems thinking, which also map onto realist and post-structural ontologies. Realist systems describe hierarchies of systems that contain 'nested' subsystems, not unlike 
a Russian matryoshka doll (Midgley, 2000). This metaphor assumes the objective reality of systems, however, as valid and extant social institutions and functions.

Several questions have been posed of structural-functionalism, GSA's ontological foundation, by the systems thinking community. Can we assume that complex systems behave predictably? Are healthy systems stable? Are stable systems 'just'? At the root of such questions is the concern that structural-functionalism, and in this case GSA, could become oblivious to the contingency of a particular governance system itself. This contingency is as much practical as it is ethical. First, the system is a product of an incalculable multitude of relationships and interactions that keep it constantly changing. The uncertainty of integrated systems outcomes is due to the systems property known as 'emergence'- the revelation of a new phenomenon arising through interactions in the system, but which may not resemble the system or subsystems of its origin (Ison, 2008). Second, if the system is contingent, partial and likely to change, on what ethical and political basis is using this model appropriate for decisions (Valero-Silva, 1996)?

This realist notion of the systems and their structures is contested by the post-structuralist approaches of CST thinkers such as Taket \& White (1993), Valero-Silva (1996), Brocklesby and Cummings (1996) and Midgley (2000). The alternative account of 'systemic' thinking is grounded in the proposition that reality, or realities, are in fact subjective and/or historically contingent and that a particular reality or way of being may be named or otherwise established by boundaries constituting a 'knowledge generating system' for the knower or the subject (Midgley, 2000, p. 76). Such boundaries, therefore, have profound ethical and political implications as they establish what elements of being and existence fall on which side of binaries such as true/false and right/wrong.

To respond to these concerns in terms of systems thinking, a distinction has been made between adopting a systematic or systemic perspective as exclusivist and inclusive connotations. Systematic practice can be characterised as goal-oriented behaviour that seeks to describe or discover an extant system that it takes to be natural, where what is considered to be relevant knowledge (true and right) is unquestioned, even though it may in practice emanate from an exclusive group of people (Ison, 2008). In contrast, systemic practice actively facilitates learning and change to accommodate a plurality of interests (Ison, 2008), 
which is responsive to post-structuralist concerns. GSA has its roots in structural-functionalism, which is closely related to realist and systematic approaches, yet it also adopts deliberative, even emancipatory practices (Potts et al., 2014). Thus, GSA attempts to operate within both systemic and systematic methodologies, but without explicit consideration of the philosophical distinctions between realist approaches and post-structural ones or the constraining effects of systematic practice on systemic modes of engagement with questions of power and emancipation. As such, there is a currently a gap between GSA's participatory aspirations and its practical approach to systemic thinking.

GSA does see itself as enabling greater visibility and effectiveness of actors as part of a system that is to make explicit a boundary definition. However, its current failure to theorise multiplicity, difference and irreducibility is a limitation. Systems thinking that places emphasis on structure and function does not see the assumed legitimacy of extant actors as contingent on particular power relations. As such, the emancipatory implications of power struggles can be underdeveloped. Peoples' values, knowledges, paradigms and cultural interpretations of governance are rendered less visible by GSA's theoretical framework and practical toolkit, as is the possibility that these can always change and that previously visible and legitimate actors may come to be contested by an array of alterative bodies and positions. GSA attempts to build a more consensusoriented representational tool to be used to make co-constructed meaning. However, because complexity also occurs at an ontological and epistemological level through different worldviews, governmental rationales and organisational narratives, such a representative tool is likely to be controversial and interpreted in multiple ways as 'people come to appreciate a quite different systemic quality to their existence' (Flood, 2010 , p. 275). In this regard, GSA's structural-functionalist ontology and epistemology becomes harder to marry with its participatory and deliberative intent as the implicitly realist approach potentially hides from view those agents who work beyond the realist account of modernity's political institutions and functions. 


\section{Using Critical Systems Thinking to Refine Governance Systems Analysis}

CST is a framework that brings critical theory's broad ontological and epistemological influences into a systemic mode of thinking about social complexity (Flood, 2010; Fuchs \& Hofkirchner, 2009; Jackson, 1991, 2010; Midgley, 2000; Valero-Silva, 1996). CST is framed through core values, themed around critique that is often expressed as systemic boundary reflection, pluralism or a manner of allowing for a multiplicity of theories and methodologies, or ontologies and epistemologies, and emancipation as some way of allowing for social improvement or the freedom to change. These core values are expressed by Flood (2010) as six commitments-the systems thinking idea, critical awareness, theoretical pluralism, methodological pluralism, social awareness and human emancipation. After a brief introduction to CST as a whole, these commitments are discussed below. To demonstrate the significance of this theoretical framework for an intervention tool such as GSA, the following sections also draw on Midgley's (2000) methodology for practice grounded in CST.

The starting point of a CST analysis is to assume that everything in the universe is directly or indirectly connected, but that a 'God's eye' view of that interconnectedness is impossible (Midgley, 2000). To combat the inevitable limits to understanding and to enable discussion, we apply 'boundaries' around knowledge. Systemic intervention seeks to explore these boundaries proceeding on the principle that a boundary indicates not only what is included but also that something is excluded (Midgley \& Richardson, 2007). These elements, be they people, objects, or values, are distinguished from that which they are not, which comes to be distinguished in turn with reference to another boundary (Midgley, 2000). Thus, in post-structuralist terms, we could say that meaning and reality are produced through the (re)articulation of boundaries which are inherently political (Laclau \& Mouffe, 2001). With this in mind, boundary critique and boundary judgment are not just innocuous forms of examining the limits of the system but are inevitably political processes for bounding systemic intervention practice.

Midgley (2000) makes the system and its contingency explicit by making 'first and second boundary judgments' explicit. Making judgments about primary boundaries, their placement and content of its system can be 
made when looking 'outward' from within the system towards the world. This is called making a first-order judgment. When looking 'back' at the knowledge system that produced the outward judgment, we are engaged in second-order judgments (Midgley, 2000). Second-order boundary judgments denote the system's identity and the contingency of this identity on first-order judgments. Second-order judgments are dependent on there being a first-order judgment; however, second-order judgments do not automatically proceed from the first and must be a deliberate practice of critiquing one's own knowledge.

We propose that this process of first and second boundary judgments can be applied to the use of GSA and systemic intervention. GSA is capable of making first-order boundary judgments, but is limited in its capacity for second-order judgments or critique of the system it takes for granted. Electing to use systemic intervention enables practitioners to come to know the systems themselves and, therefore, question the ontologies and epistemologies on which the account of the system is based, and the way that system is governed based on these knowledges and ways of knowing. The process of constant iteration and reflection between the first- and second-order judgments are analytically essential as it is this process that contributes to the growth of knowledge and emancipatory potential by highlighting the contingency of the system, thus allowing other ways of being to be entertained within the system. The following sections use CST's six core commitments to organise GSA and CST's sets of reflective practices. We highlight occasions where GSA expresses a similar account of emancipation to those expressed by CST scholars and practitioners. However, we also note differences in accounting for power, knowledge and emancipation. In some cases, these sections also reflect on the rift within CST that reflects the breadth of critical theory, including the debate between consensus and incommensurability that we have chosen to represent through Habermas and Foucault. Within each commitment, implications for GSA as a practical tool are explored through a comparison with systemic intervention, as a praxis methodology for CST.

\section{Systems Thinking Idea}

The first of CST's core commitments is the systems thinking idea-the idea that valid knowledge and meaningful understanding comes from building up whole pictures of phenomena, not by breaking them into parts (Flood, 2010). This core understanding is present in the GSA 
framework. GSA attempts to benchmark systems to determine how the 'Systemic functionality (i.e. how parts of the system work) across and within structures serves to reinforce and maintain the stability of the system's structures' in the context of an ever-changing, complex and unpredictable environment (Dale, Vella, Pressey et al., 2013, p. 10). These are examples of first-order boundary judgments, concerned with questions of the system's core characteristics and attributes. However, GSA makes the ontological and epistemological assumption that these can be known, by all, at a given point in time. The framework draws on functions to describe the way in which structures are produced and operated and related to subsystems. For governance systems, three 'cornerstone functional elements' are identified (Dale \& Bellamy, 1998) as knowledge application to improve governance systems, connection of effort within governance systems and decision-making capacity of players within the system (agency).

It is through these three functional and across different structural elements that GSA analysis is organised throughout each stage of its analysis. 'Knowledge application' to improve governance systems implies the presence of several CST core commitments - critical awareness, theoretical plurality and methodological plurality. The 'connection of effort' within governance systems entails both the systems idea and social awareness. The decision-making capacity of players within the system engages with the emancipatory, critical awareness and social awareness commitments, each of which are discussed in detail in the relevant following sections.

Despite GSA's grounding in structural-functionalism, it recognises that systems are complex, may transform and 'consist of many component parts that contribute towards the overall operability of the system' (Potts et al., 2014, p. 2), and it references concerns with agency and processes to achieve a more ethical and efficacious outcome involving multiple stakeholders in complex problems. However, functions themselves do little work to analyse these relationships, as they tend to refer to what the relationship achieves, rather than how it is constituted-namely through particular power relations mediated and produced by knowledge and its communication (Foucault, 2000). It is relations of power and communication (described in post-structuralist literatures as power and knowledge) that produce emergence (Foucault, 2000) and are, therefore, central concepts to a systemic analysis of governance (Brocklesby \& Cummings, 1996; Valero-Silva, 1996) or to an analysis of governance as emerging from and harnessing systemic emergence (Dillon, 2000, 
2007; Dillon \& Reid, 2009). The remainder of CST's core commitments enable engagement with the contingency of the particular system that the systems thinking idea makes space for, which are developed below in terms of GSA to help it move beyond first order boundary critique.

\section{Critical Awareness}

The second CST commitment is critical awareness, demonstrated when the underlying assumptions of a system are made explicit and open to questioning, which we have argued is currently limited in GSA. Critical awareness is an applied second-order boundary critique that encourages an exploration of the ontology, epistemology, methods and techniques used in governance analysis. However, it is important to understand what is meant by the term 'critical'. As previously mentioned, critical theory, loosely used, often obscures the differences between Habermasian critical theorists and post-structuralist thinkers such as Foucault. While CST has been largely dominated by Habermasian accounts, we seek to explore a more critical Foucauldian account here. A Habermasian approach to CST understands that human liberation can be achieved by changing the material conditions in which people live, work and socialise. Therefore, CST practitioners would be more likely to promote expert-led interventions into problematic situations in which some improvement is sought, meaning that critical thinking can be of an instrumental nature (Valero-Silva, 1996). This is similar to the current approach of GSA. However, for post-structuralist thinkers, liberation is enabled through 'The provision of tools for thinking critically, so as to enable individuals to gain control for themselves [of] a greater sense of self "unfettered-ness" (Brocklesby \& Cummings, 1996, p. 751). To make the ethical stakes of this distinction clear, Valero-Silva (1996, p. 74) noted:

we should concentrate our efforts on understanding the relationship between the different methodologies and the shared cultural practices that have shaped what we are. In this sense, the systems methodologies are not only disciplinary techniques for the normalisation of individuals within organisations according to a particular rationality, but also expressions of wider disciplinary mechanisms in contemporary society.

Critical awareness enables us to observe that the values or practices that might be understood as emancipatory actions to some may be seen as 'problems' or 'weaknesses' of the system to others. The issue, therefore, 
is the unquestioned use of universalising concepts by practitionersconcepts such as 'emancipation', 'improvement' and 'participation' can assume the validity of the extant system. Post-structuralists do not doubt that 'improvements' are achievable and meaningful, but they see these as defined by their particular knowledge systems, rather than as necessarily universally good (Hewlett, 2007; Rancière, 2007; Rancière et al., 2001). What is rejected here is not emancipation per se, but the binding of emancipation to the assumed developmental march of human progress and to a single account of the good society. This also has implications for the practice of intervention, as Valero-Silva (1996, p. 77) stated:

the practitioner must realise that his/her intervention would be framed within the unchallenged acceptance of certain boundaries and rationalities-unchallenged assumptions that made possible the very existence of management sciences and the organisations $s /$ he is helping, the same ones that make possible his/her intervention in the first place.

The commitment of critical awareness in both systemic intervention and GSA practitioners can start with a rigorous first-order boundary critique, an effort to articulate 'who' and 'what' is to be included, but then to move beyond this to a second-order critique that seeks to reveal the power/knowledge relations that are perhaps more hidden or presented as unavoidable and logical in the constitution of the system (Valero-Silva, 1996). GSA's grounding in structural-functional thinking has a pragmatic intention to demonstrate critical awareness through opening dialogue to identify the components of a system and the work that each does towards building a holistic model. GSA's authors contend that systemic components may be broadly inclusive of government agencies or civil society groups, or, at a different scale, Indigenous governance systems, local organisations, communities or individuals, and provide the example of individual parents, teachers and students in a school system (Potts et al., 2014). GSA assumes each of these have some degree of decision-making capacity, connectivity and use knowledge within the system.

If we are to honour the spirit of CST's core commitments, the question of knowledge extends from what knowledge is present and whether it is used to how knowledge is produced and by whom in the process of making boundary decisions - that is, the active (re)articulation of the system. If, in analysing this, we only focus on the content of an established body of knowledge, we assume that its particular perspective is unquestionable. Second-order boundary critique examines the contingency of knowledge 
itself that within the systems paradigm is the product of emergent relations of knowledge and power. Identifying knowledges, questioning the 'changes, and the processes that lead to them' (Valero-Silva, 1996, p. 76) and their agents as participants and interventionists, in a contingent space of knowledge production, is essential in considering the ethics and politics of different possible actions. Building on GSA's good intentions then, systemic intervention provides a model for how these concerns can be addressed by asking who is accounting for good and bad here? What knowledges and ways of knowing are included or excluded and why or how? For this reason, applied CST methodology is participatory in practice and concerned with actively preventing power abuses through research and consequent decision-making. Individual and social knowledge is generated by the process facilitating generative, rather than linear or normative change, which is a potential outcome of GSA unless practices that enable critical awareness are explicitly adopted.

Within CST, there is an explicit commitment to always engage at the level of the individual regardless of scale. This disrupts the assumed validity of more established, larger institutions and structures. It also enables practitioners and participants to make sense of the actual operation of power in performing particular functions. Clearly, a critical attitude necessary for second-order boundary critique is present here, and with the adaptation of a boundary critique process, practitioners and participants are enabled to decide which boundaries are to change and the change processes that are to occur.

\section{Theoretical Pluralism}

The third commitment is theoretical pluralism, which is based on the avoidance of establishing a single theoretical approach or an exclusive ontology and epistemology. This commitment asks us not to work with one single account of the world as if it is the only one. Neither does it seek to establish a particular account of the world as the only one. Rather, an acceptance of the incommensurability of ways of knowing and ways of being allows for all paradigms that have existed to exist simultaneously and continue to exist and change (Flood, 2010). This commitment has significant philosophical implications for the status of systemic approaches themselves, as necessarily partial. It also suggests that emancipation is not necessarily a single or shared state and that it might occur in a multitude of different ways. As such, practitioners need not 
(indeed, should not) appropriate the uniqueness of others in the name of a single theory to explain the whole world or system. They should also accept that emancipation can be multiple and irreducible, such that no single, universal account of what is 'right' or 'good' will ever be sufficient (Brocklesby \& Cummings, 1996), and that such an assumption could in fact do violence to these other ways of being.

In practical terms, theoretical pluralism enables context-driven, open engagement with multiple theoretical approaches (Gregory, 1996). Its goal is to allow alternative, incommensurate, epistemologies and ontologies to engage with each other in a 'localised' practice of making boundary judgments and generating new knowledge. Different approaches, while equally present, provide space to explore the irreducibility of ways of knowing and being through the differences between and distinctiveness of each.

All players within the system, from elected legislatures to street-level bureaucrats (Lipsky \& Hill, 1993) and activists, can choose to accept paradigms as multiple, discordant and incommensurable. A second-order critique reveals differences and exclusions. Competing and conflicting perspectives may appear to be localised, contingent and historically situated, but nonetheless embody tensions and ambiguities. An acceptance, or even critical appreciation of difference, has the potential to enrich our understanding of the complex governance problem. The value to systemic intervention practice and the GSA framework is that the discordant pluralism or theoretical pluralism perspective provides an ethical foundation for decision-making that denies the need for an 'either/or' reduction, as the juxtaposition of oppositional viewpoints are supported as a both/and position (Gregory, 1996).

\section{Methodological Pluralism}

Methodological pluralism, the fourth commitment, is closely related to theoretical pluralism. It shares the principle that there is no universal theory and that adopting one would necessarily preclude the full realisation of others (Midgley, 1996, 2000). Thus, we are left with a variety of methods and the knowledge that each privileges particular ontologies and epistemologies over others (Midgley, 2000), and that we need to be attentive to this in when and how we use such methods. Pluralism can then be a methodological tool for choosing between different methods 
that bring differing and perhaps incompatible philosophical foundations to the table while committing to a broad repertoire of methods that nonetheless affect particular kinds of change or analysis in particular ways. Through the practical application of second-order boundary critique we can draw on, learn from and purposefully mix methods (Midgley, 2000). Doing so allows participants to bring alternative knowledge to the table and bring new knowledge into being-they learn from critical reflection and build shared understandings in an ongoing cyclical application of philosophy to methodology, leading to generative and original responses to particular problems, the boundaries of which are also critically engaged with. An ethical model of learning uses theoretical and methodological pluralism to activate one another by building the methodological skills and repertoires of the practitioners, asking penetrating questions of the theoretical assumptions underlying a method or the intervention and critically reflecting on the practitioner's practice and finding gaps between the espoused methodology of the practitioner and stakeholders' interpretations of the methodology in use (Midgley, 2000).

If choices are made by experts with regard to the most suitable and appropriate methods for the intended purpose of a project, they do not open themselves up to this methodological pluralism and, therefore, may allow implicit and explicit assumptions to remain unexamined. Systemic intervention requires that practitioners acknowledge these. Making such theoretical and methodological decisions in an open context is the practice of emancipation itself, as it allows space for the emergence of knowledge and being. As such, we are enslaved and emancipated in relation to the methods for understanding and accounting for our internalised and extant rationalities and their technologies (Brocklesby \& Cummings, 1996). GSA is intended as a framework methodology within which multiple sub-methodologies might be applied to enhance analysis. In this sense, it strongly recognises multiple methodology principles. GSA as a framework method, however, could better acknowledge the role of methodology in both emancipating and enslaving, which will enable it to acknowledge that its methodological accounting for governance is partial and can be situated in a more open approach to framework methods for reforming governance. 


\section{Social Awareness}

The fifth commitment, social awareness, seeks to identify the power relations at work in society that implicitly and explicitly work to legitimise or delegitimise particular practices. Both GSA and the systemic intervention approach are intended to deal with complex social relations. In the GSA literature, Potts et al. (2014) drew on Buchy and Race (2001) to acknowledge that public participation can result in challenges to existing power structures, the outcome of which may result in empowering stakeholders. Without an explicit secondary boundary analysis of the social nature of the system, it seems that the emancipatory outcomes of using GSA are less likely to be the outcome of methodological design than they are the unexpected product of emergence. In the absence of a clear commitment to emancipatory outcomes, it is conceivable that participatory methods in GSA are constrained by implicit assumptions about who should participate and how governance should be 'known' and 'done'.

However, social awareness extends much further. For the GSA framework, which relies heavily on an expert-facilitated approach to governance analysis, the associated power of the expert must be critically reviewed through self-reflexivity and being open to critique from others. There has been a longstanding critique of such expert roles (Taket \& White, 1994) and whether and how stakeholders may or may not agree with the expert's priorities (Ferreyra, 2006). The actions of experts and researchers need to be considered in terms of the effects they might have on participants during the course of the intervention. The very act of an intervention into any system assumes both the necessity and validity of questioning the extant system and, as such, is political as it could reinforce or challenge power relations and dynamics. Thus, any agent of intervention needs to be as aware as possible of extant power relations to avoid unintended consequences and cause the least amount of unauthorised disruption possible. In this analytical exercise, it should also be made explicit, and considered at the ethical and political level, as to what implications (non-) intervention might have. GSA needs to better consider how it will be imbricated in an array of power relations, how any intervention might affect this system, and proceed with appropriate sensitivity to the wider society that may not be commensurable with the Western norms of governance and the Western form of life these modes of governance often seek to produce. 


\section{Human Emancipation}

The sixth commitment, human emancipation, is the overriding commitment to which all the other commitments are geared. Human emancipation cannot be achieved unless the explicit role of power relations in the shaping of individuals as subjects is articulated. Through systems of power relations, human emancipation is inherently related to the operation of power. Crucially, for both CST and GSA, the ontological distinctions in how power and knowledge are accounted for has major implications for how emancipation is conceptualised. A Habermasian view regards power as exerted 'over' people and a relatively 'equal' power situation is assumed to enable collective emancipation (Brocklesby \& Cummings, 1996; Ashenden \& Owen, 1999; Valero-Silva, 1996). A Foucauldian account, however, states that power is 'always already' and 'everywhere'-power is the connection or 'strategic web' between people and things and that this is productive and inhibitive (Foucault, 2000). Power is not inherently bad or good, but it can be modulated and changed within and between particular power relationships. If power is always contingent and present only in its enactment between the people and the things of complex systems (Foucault, 2000), resistance is just as particular and momentary. Emancipation, by this account, is the ability of individuals and collectives to self-order their identities and practices, rather than being altered by someone or something else from one relation or systemic state to another specified form of relation or state. In Midgley's (2000) terms, emancipation is 'improvement', but one that is temporally and locally defined and will be viewed differently between agents with differing ontological worldviews, applying their own boundary judgments, values and ethics from their particularly situated position.

These distinctions have enormous implications for our practice and the role of first- and second-order boundary critique. Taking the GSA, which sits closer to a Habermasian approach in so far as it strives towards consensus making, experts may be seen to be able to emancipate, or improve, situations through the force of a better argument. Yet, the Foucauldian view notes the contingency of knowledge and identity and, therefore, that the designation of an expert to intervene may be a dangerous proposition as their knowledge, while it may not be 'wrong', is also not universally 'right'. As Levin (1994, pp. 26-27) stated, '[Practitioners] can [either] support a micro-emancipation process or they can act as suppressors'. So while individual emancipatory actions could come together in either 
collaboration or a collective endeavour, its realisation may not be universal or collective. Everyone's emancipation will be partly the product of their situatedness.

Clearly, the choice to extend the analysis to involve a second-order critique, in keeping with systemic intervention, resides in the degree of recognised incommensurability within the problem situation. The awareness of self-emancipation must be able to be developed, practised and opted out of as openly as possible. That is, no system or form of system should be assumed to be valid or invalid — the 'natural order' of things is questionable and the situation we find ourselves in can be reordered. The objective is not the development of a 'better' argument that will provide a 'better' system for all, but an ethos for the development of an undefined, open outcome that will be particular and contingent for its place and time, and for the people who developed it. In terms of collective emancipation, and the transformation of institutions, the trick here is to not to assume or enforce institutions or their rulings as universal in space and time. Emancipation is in the practice of the journey, rather than the arrival at a destination. For GSA, in its structural-functionalism-informed approach, emancipation as a practice is not highly visible and instead is assumed to reside in the perfection of the system, potentially disallowing emancipation itself.

So, what is the role of the academic, policy officer, activist or consultant if the better argument is not 'better' but just useful, absorbable or believable in particular ways to particular people, in a particular place and time, with particular power relations in play? For systemic interventionists, no particular system is 'right' per se, rather, it is the processes through which systems are constituted, emerge and change that are the places and moments of emancipation:

The contradiction and real challenge in this process is how to integrate professional skill and knowledge in the participants' struggle to develop control over their own situation. Accordingly, emancipation is linked to and cannot be separated from the process by which it is acquired. (Levin, 1994, p. 28)

Does this prevent any system-wide social emancipation? Less hierarchical systems allow more flexibility and the potential for emancipatory change for both the system as a whole and individuals within it, but the system itself is not emancipated per se. Indeed, based on principles of irreducible difference, it cannot be. Emancipation is a practice and the nature of people's 
participation in change practices, including of governance systems, is crucial and enabled by second-order boundary critique of those systems (Midgley, 2000). Participation in the process is initiated by a dialogue that should make explicit what is included in the first- and second-order boundary critique. Systemic intervention might explore contingency, forms of power, relations of power and inherent limitations-fallibility and practicalitiesin the here and now. However, such openness itself enables emergence and the ability for each and every participant to 'emancipate from where they are' situated in the system at that moment.

\section{Discussion}

The previous sections have identified CST's six commitments and how the systemic intervention approach would supplement GSA's own processes to enable more attention to, and allowance of, the multiplicity and irreducibility of ways of knowing and being. Repositioning GSA in this way allows it to be a more nuanced analytical and intervention tool, with several implications for practice. First, it is important to note that use of the second-order boundary critique for governance analysis is inherently political in that it questions the nature of the social order and, in so doing, allows for other ways of being and for the possibility of change. As such, it does not assume that norms of governance, their institutions or their agents are necessary or right, nor does it inherently assume that they should or will remain the only approaches to governance. For Northern Australia, Indigenous governance and ways of being are grounded in its incommensurability with Western norms of governance, and even Western modes of governance are fragmented and conflicting as a result of state, territory and federal political structures (Stephens et al., 2014). In this context, second-order boundary critique allows for acknowledgement of these differences and crucially respect for them to remain different, rather than assuming they must be subsumed into a coherent single system, particularly one predicated on the dominant Western model.

A deeply nuanced, critical and emancipatory stance matters because governance practices profoundly shape the lives of the population and landscape. GSA is, of course, just one of many approaches for looking at broader governance systems, but as GSA is a tool that is being used in practice in Northern Australia and as emancipation is itself a practice, it is essential that where it is used it enables, rather than shuts down, difference. In Northern Australia, the tool is currently being used in relation to NRM 
and social policy. In such cases, second-order boundary critique and consideration of CST's six commitments gives space to a broader pool of stakeholders, ontologies, epistemologies and outcomes. GSA could more explicitly apply these considerations to better identify its own role in these deeply political and ethical engagements with difference and identify how its own practice may or may not enable emancipatory action. There is also a challenge here for CST in its engagement with questions of governance and systems of governance as to whether a more systemic approach to these can be developed. There has been limited engagement from the CST literature with governance in terms of Foucauldian thought, particularly on liberal governmentality and bio-politics, while the last decade or so has seen much more engagement from post-structuralist scholars with complexity (Cilliers, 1998; Dillon, 2007; Olssen, 2008; Urry, 2005). As such, much of the groundwork is now laid for CST to re-engage with post-structuralist approaches once more, particularly in relation to questions of ethics, the political and practice.

Governance is no longer understood as being solely located in the institutions of formal government and its implications for emancipation are often more difficult to discern as the power and knowledge relationships are less readily identifiable but nonetheless powerful. As such, rather than large-scale shifts in overall system structure determined by a universal and singular account of the 'good life' and the 'public good', there has been a shift to a focus on localised and relational practices as the places or moments where governance occurs and where they can be critiqued or changed. CST and systemic intervention provide GSA with an enhanced set of conceptual and practice tools to support its goal of participatory approaches in this context. In Northern Australia, where divergences between governance systems are wide and where accounts of what is a 'good' life also vary immensely, there is a particular need to engage with gradual 'ground up approaches' to 'going on together' (Christie, 2006; Stephens et al., 2014). CST and systemic intervention provide a route for GSA into considering and engaging with such alternative methodologies and theories through allowing for pluralism.

The lessons for GSA and mainstream governance approaches come amid a growing concern, nationally and internationally, about ongoing harm to people, cultures and the environment in Northern Australia (Dale, 2014). The failure to resolve ongoing social inequality concerning Indigenous Australians, treatment of people seeking political and economic asylum in Australia and the threatened extinction and destruction of ecological 
systems of global significance such as the Great Barrier Reef all belie a deeper ontological form of 'inequality' where existing ontological and epistemological difference is obfuscated while the repercussions of this denial are magnified. By taking these challenges seriously, this political moment could also enable the rethinking of Northern Australia and its governance systems, not only for national, state and territory governments, but for local populations and their diverse worlds. A supplemented approach to GSA could help engage with mainstream government practices to find (re)solutions-not necessarily as in 'closure', but as 'agreements' of processes that move us onwards in an ethical fashion. One clear example of boundary critique is that to create 'new' agreements and ways of being, individuals and groups must be courageous enough to recognise different accounts of the social body, past and present. Reconciliation (as opposed to reparation, retribution or retaliation) is a generative process that allows new ways of being to emerge yet accepts multiplicities, incommensurability and the irresolvability of different ways of being (Hewlett, 2010; McDonough, 2009; Rancière et al., 2001).

Such a radically political democratisation of GSA and decision-making changes the emphasis of interventions to processes and relationships and focuses less on the proposed outcome. It changes our understanding and expectations of the analysis process; in this case, shifting GSA from a systematic procedure to a systemic practice where primacy is granted to knowledge creation, from the nature of a 'knowledge generating system' or institution itself to the process of generating that knowledge (Bawden, 2003; Midgley, 2000). As such, the question becomes not 'what is the system?', but 'how do we know the system?' and 'how do we "do" or "perform" this system?' The intellectual capacity to question the foundational rules of the system (its ontology and epistemology) is the highest level of understanding and critique of a system (Meadows, 1999) and the most profound point at which to make space for systemic change.

\section{Conclusion}

This chapter has demonstrated how CST can supplement GSA to enable an awareness of multiplicity and incommensurability that enables the perusal of emancipation as a practice that is not predicated on the perfection of a Western system of governance and government, while also acknowledging that such institutions play a significant role in the 
production of the wider social and ecological system. As such, GSA is able to adopt a systemic rather than systematic approach. For practical reasons, GSA had intentionally established its framework internally within the norms of Western governance practices, rather than engaging externally with them. By doing so, it adopted an implicitly foundationalist and universalist ontology and epistemology that could co-opt or exclude different ways of being. For the purpose of critical engagement with GSA, we drew on an account of CST that takes seriously poststructuralist and anti-foundationalist belief in the irreducibility of ways of being, acknowledges multiplicity and its loss through foundationalist practices, adopts Foucauldian analyses of power and knowledge and attempts to deliberately conduct boundary critique of systems to achieve a critical stance.

In particular, this chapter has outlined the value of undertaking a secondary boundary critique through the lens of CST's six core commitments that, when applied, can assist GSA in making ethical interventions in governance systems sensitive to power, knowledge and emancipation. This does not make it relativist. Rather, the theoretical and methodological pluralism proposed, premised on multiplicity and irreducibility of different ways of being and knowing, makes sure that questions of intervention are seen as properly ethical and political in their most fundamental and profound sense and are engaged with in that fashion. As Brocklesby and Cummings (1996, p. 751) stated, this does not mean that 'anything goes, rather [that] everything depends' (emphasis original). Therefore, rather than seeking a consensus, this repositioned account of GSA seeks a 'consent to act' (Brocklesby \& Cummings, 1996, p. 751 [emphasis original]) for a limited period and fashion, with recognition of its situatedness, limitations and assumptions to enhance its utility and validity in Northern Australia, or indeed anywhere else where difference plays such a profound role in the tensions over the shaping of people's lives and the landscape.

\section{References}

Abrahams, H. (2005). Devolution enhances integration. Australasian Journal of Environmental Management, 12(supp1), 57-61.

Althaus, C., Bridgman, P. \& Davis, G. (2007). The Australian policy handbook (4th ed.). Crows Nest, NSW: Allen \& Unwin. 
Anderson, I. (2015). The crisis of Australia's Indigenous policy. Meanjin, 74(3), 54-59.

Ashenden, S. \& Owen, D. (1999). Foucault contra Habermas. London, England: SAGE.

Bausch, K. C. (2001). The emerging consensus in social systems theory. Springer.

Bawden, R. (2003). Book review. Systemic intervention: Philosophy, methodology, and practice. Contemporary systems thinking. Systemic Practice and Action Research, 16(5), 369-372.

Beaumont, J. \& Nicholls, W. (2008). Plural governance, participation and democracy in cities. International Journal of Urban and Regional Research, 32(1), 87-94.

Bellamy, J., Walker, D., McDonald, G. \& Syme, G. (2001). A systems approach to the evaluation of natural resource management initiatives. Journal of Environmental Management, 63, 407-423.

Bevir, M. (2010). Rethinking governmentality: Towards genealogies of governance. European Journal of Social Theory, 13(4), 423-441.

Brocklesby, J. \& Cummings, S. (1996). Foucault plays Habermas: An alternative philosophical underpinning for critical systems thinking. Journal of the Operational Research Society, 47, 741-754.

Buchy, M. \& Race, D. (2001). The twists and turns of community participation in natural resource management in Australia: What is missing? Journal of Environmental Planning and Management, 44(3), 293-308.

Carman, J. G. (2007). Evaluation practice among community-based organizations research into the reality. American Journal of Evaluation, 28(1), 60-75.

Castells, M. (2000). The rise of network society (vol. 1). Malden, MA: Blackwell.

Christie, M. (2006). Transdisciplinary research and Aboriginal knowledge. The Australian Journal of Indigenous Education, 35, 78.

Christie, M. (2014). Decolonizing methodology in an Arnhem Land Garden. In B. N. K. Schaffer (Ed.), Decolonizing the landscape: Indigenous cultures in Australia (pp. 57-69). Amsterdam, The Netherlands; New York, NY: Rodopi.

Cilliers, P. (1998). Complexity and postmodernism: Understanding complex systems. London, England: Routledge. 
Connick, S. \& Innes, J. (2003). Outcomes of collaborative water policy making: Applying complexity thinking to evaluation. Journal of Environmental Planning and Management, 46(2), 177-197.

Curtis, A., Robertson, A. \& Race, D. (1998). Lessons from recent evaluations of natural resource management programs in Australia. Journal of Environmental Management, 5(2), 109-119.

Dale, A. P. (1993). An assessment of planning for government-funded landuse development projects for Aboriginal communities in Eastern Australia (unpublished doctoral thesis). Griffith University, Qld.

Dale, A. P. (2013). Governance challenges for Northern Australia. Cairns, Qld: Cairns Institute, James Cook University.

Dale, A. P. (2014). Beyond the north-south culture wars: Reconciling Northern Australia's recent past with its future. Springer.

Dale, A. \& Bellamy, J. (1998). Regional resource use planning: An Australian review (LWRRDC Occasional Paper 9/98). Canberra, ACT: Land and Water Resources Research and Development Corporation.

Dale, A. P. \& Lane, M. B. (1993). Strategic perspective analysis: A procedure for participatory and political social impact assessment. Society and Natural Resources, 7(3), 253-267.

Dale, A. P., Vella, K. \& Potts, R. (2013). Governance Systems Analysis (GSA): A framework for reforming governance systems. Journal of Public Administration and Governance, 3(3), 162-182. doi.org/10.5296/jpag.v3i3.4385

Dale, A. P., Vella, K., Pressey, R. L., Brodie, J., Yorkston, H. \& Potts, R. (2013). A method for risk analysis across governance systems: A Great Barrier Reef case study. Environmental Research Letters, 8(1), 1-16.

Dean, M. \& Hindess, B. (1998). Governing Australia: Studies in contemporary rationalities of government. Cambridge University Press.

Dillon, M. (2000). Poststructuralism, complexity and poetics. Theory, Culture \& Society, 17(5), 1-26.

Dillon, M. (2007). Governing through contingency: The security of biopolitical governance. Political Geography, 26(1), 41-47.

Dillon, M. \& Reid, J. (2009). The liberal way of war: Killing to make life live. London, England: Routledge. 
Ferreyra, C. (2006). Practicality, positionality, and emancipation: Reflections on participatory action research with a watershed partnership. Systemic Practice and Action Research, 19(6), 577-598.

Flood, R. L. (2010). The relationship of 'systems thinking' to action research. Systemic Practice and Action Research, 23(4), 269-284. doi.org/10.1007/ s11213-010-9169-1

Forester, J. (1999). The deliberative practitioner: Encouraging participatory planning processes. MIT Press.

Foucault, M. (2000). Essential works of Foucault 1954-1984. Volume 3: Power. New York, NY: New Press.

Fuchs, C. \& Hofkirchner, W. (2009). Autopoiesis and critical social systems theory. In R. Magalhães \& R. Sanchez (Eds), Autopoiesis in organization theory and practice (pp. 111-129). Bingley, England: Emerald.

Gregory, W. (1996). Dealing with diversity. In R. L. Flood \& N. R. A. Romm (Eds), Critical systems thinking, current research and practice (pp. 37-59). London, England: Plenum.

Hajkowicz, S. (2009). The evolution of Australia's natural resource management programs: Towards improved targeting and evaluation of investments. Land Use Policy, 26, 471-478.

Hewlett, N. (2007). Badiou, Balibar, Rancière: Re-thinking emancipation. London, England: Continuum.

Hewlett, N. (2010). Badiou, Balibar, Rancière: Re-thinking emancipation. A\&C Black.

Hoggarth, L. (2010). A practical guide to outcome evaluation. Jessica Kingsley Publishers.

Ison, R. L. (2008). Systems thinking and practice for action research. In P. Reason \& H. Bradbury (Eds), The Sage handbook of action research participative inquiry and practice (2nd ed.) (pp. 139-158). London, England: SAGE.

Jackson, M. C. (1991). The origins and nature of critical systems thinking. Systems Practice, 4(2), 131-149. doi.org/10.1007/BF01068246

Jackson, M. C. (2010). Reflections on the development and contribution of critical systems thinking and practice. Systems Research and Behavioral Science, 27(2), 133-139. doi.org/10.1002/sres.1020

Laclau, E. \& Mouffe, C. (2001). Hegemony and socialist strategy: Towards a radical democratic politics. London, England: Verso. 
Lane, M. B. (2005). Public participation in planning: An intellectual history. Australian Geographer, 36(3), 283-299.

Lefevre, C. (1998). Metropolitan government and governance in western countries: A critical review. International Journal of Urban and Regional Research, 22(1), 9-25. doi.org/10.1111/1468-2427.00120

Lemke, T. (2002). Foucault, governmentality, and critique. Rethinking Marxism, 14(3), 49-64.

Levin, M. (1994). Action research and critical systems thinking: Two icons carved out of the same log? Systems Practice, 7(1), 25-41.

Lipsky, M. \& Hill, M. (1993). Street-level bureaucracy: An introduction. In M. Hill (Ed.), The policy process: A reader (pp. 381-385). London, England: Harvester Wheatsheaf.

Maani, K. \& Cavana, R. (2000). Systems thinking and modelling: Understanding change and complexity. Auckland, New Zealand: Prentice Hall.

McDonough, T. (2009). The hypothesis of incommensurability and multicultural education. Journal of Philosophy of Education, 43(2), 203-221.

McMullen, J. (2013). Dispossession neo-liberalism and the struggle for Aboriginal land and rights in the 21st century. In R. Craven, A. Dilton \& N. Parbury (Eds), Black \& white: Australians all at the crossroads (pp. 105-126). Ballan, Vic.: Connor Court.

Meadows, H. D. (1999). Leverage points: Places to intervene in a system. Retrieved from donellameadows.org/archives/leverage-points-places-to-intervene-in-asystem/

Midgley, G. (1996). What is this thing called CST? In L. R. Flood \& N. R. A. Romm (Eds), Critical systems thinking: Current research and practice (pp. 11-22). New York, NY: Plenum Press.

Midgley, G. (2000). Systemic intervention: Philosophy, methodology, and practice. New York, NY: Kluwer Academic.

Midgley, G. \& Richardson, K. A. (2007). Systems thinking for community involvement in policy analysis. Emergence: Complexity and Organization, 9(1-2), 167-183.

Muro, M. \& Jeffrey, P. (2008). A critical review of the theory and application of social learning in participatory natural resource management processes. Journal of Environmental Planning and Management, 51(3), 325-344. 
Olssen, M. (2008). Foucault as complexity theorist: Overcoming the problems of classical philosophical analysis. Educational Philosophy and Theory, 4O(1), 96-117.

Parker, C. \& Braithwaite, J. (2003). Regulation. In P. Cane \& M. Tushnet (Eds), The Oxford handbook of legal studies. Oxford, England: Oxford University Press.

Parkins, J. R. \& Mitchell, R. E. (2005). Public participation as public debate: A deliberative turn in natural resource management. Society and Natural Resources, 18(6), 529-540.

Peck, J. \& Tickell, A. (2002). Neoliberalizing space. Antipode, 34(3), 380-404.

Plummer, R. \& Armitage, D. (2007). Charting the new territory of adaptive co-management: A Delphi study. Ecology and Society, 12(2), 10.

Potts, R., Vella, K., Dale, A. \& Sipe, N. (2014). Exploring the usefulness of structural-functional approaches to analyse governance of planning systems. Planning Theory, 15(2), 162-189. doi.org/10.1177/1473095214553519

Prout, S. \& Howitt, R. (2009). Frontier imaginings and subversive Indigenous spatialities. Journal of Rural Studies, 25(4), 396-403.

Rancière, J. (2007). On the shores of politics. London, England: Verso.

Rancière, J., Bowlby, R. \& Panagia, D. (2001). Ten theses on politics. Theory \& Event, 5(3). doi.org/10.1353/tae.2001.0028

Rauschmayer, F., Berghöfer, A., Omann, I. \& Zikos, D. (2009). Examining processes or/and outcomes? Evaluation concepts in European governance of natural resources. Environmental Policy and Governance, 19(3), 159-173.

Springer, S. (2010). Neoliberalism and geography: Expansions, variegations, formations. Geography Compass, 4, 1025-1038. doi.org/10.1111/j.1749-8198. 2010.00358.x

Stephens, A., Oppermann, E., Turnour, J., Brewer, T., O’Brien, C., Rayner, T., Blackwood, G. \& Dale, A. P. (2014). Identifying tensions in the development of Northern Australia: Implications for governance. Journal of Economic and Social Policy, 17(1), Article 5.

Taket, A. \& White, L. (1993). After OR: An agenda for postmodernism and poststructuralism in OR. Journal of the Operational Research Society, 44(9), 867-881.

Taket, A. \& White, L. (1994). The death of the expert. The Journal of the Operational Research Society, 45(7), 733-748. 
Trudgen, R. (2012). Why warriors lie down and die: Towards an understanding of why the aboriginal people of Arnhem Land face the greatest crisis in health and education since European contact. Why Warriors Pty Ltd.

Turnbull, W. (2005). Evaluation of current governance arrangements to support regional investment under the NHT and NAP. Canberra, ACT: Department of the Environment, Water, Heritage and the Arts and Department of Agriculture, Forestry and Fisheries.

Urry, J. (2005). The complexity turn. Theory Culture and Society, 22(1), 1-14.

Valero-Silva, N. (1996). A Foucauldian reflection on critical systems thinking. New York, NY: Plenum Press.

Verran, H. (2011). Imagining nature politics in the era of Australias emerging market in environmental services interventions. The Sociological Review, 59(3), 411-431.

Vogel, N. (2011). Analysis of performance excellence evaluations of regional natural resource management organisations. Australian Knowledge Management Group.

Woinarski, J. C. (2014). The illusion of nature: Perception and the reality of natural landscapes, as illustrated by vertebrate fauna in the Northern Territory, Australia. Ecological Management \& Restoration, 15(1), 30-33. 
This text is taken from Leading from the North: Rethinking Northern Australia Development, edited by Ruth Wallace, Sharon Harwood, Rolf Gerritsen, Bruce Prideaux, Tom Brewer, Linda Rosenman and Allan Dale, published 2021 by ANU Press, The Australian National University, Canberra, Australia. 